\title{
Open access for the medical librarian ${ }^{1}$
}

\author{
Heather Morrison and Andrew Waller
}

\begin{abstract}
In this article open access is defined, and the resources and issues of greatest relevance to the medical librarian are discussed. The economics of open access publishing is examined from the point of view of the university library. Open access resources, both journals and articles in repositories, are already significant and growing rapidly. There are close to 2300 fully open access, peer-reviewed journals listed in the Directory of Open Access Journals (DOAJ) (320 health sciences titles are included). DOAJ is adding new titles at the rate of 1.5 per day. An OAIster search of resources in repositories includes more than 7.6 million items (a rough estimate of the number of articles in repositories, although not all items are full text), and this number will exceed one billion items before the end of 2007. Medical research funders, including the US National Institutes of Health, the Wellcome Trust, the UK Medical Research Council, and the Canadian Institutes of Health Research, either have implemented or are considering open access policies. This will drive greater growth in open access resources, particularly in the area of medicine. There are implications and leadership opportunities for librarians in the open access environment.
\end{abstract}

\section{Introduction}

The open access (or OA) movement is one of the more notable developments to have emerged in the library world in the last few years. It has implications for all types of libraries and librarians, particularly in the health sciences. This paper presents some basic information about OA as well as a survey of recent OA policy developments, particularly those relevant to the medical field.

\section{Open access: a definition}

There are several definitions of open access. One of the better definitions is from the Budapest Open Archives Initiative (BOAI) (www.soros.org/openaccess). The BOAI states that OA involves "free availability on the public internet, permitting any users to read, download, copy, distribute, print, search, or link to the full texts of these articles, crawl them for indexing, pass them as data to software, or use them for any other lawful purpose, without financial, legal, or technical barriers other than those inseparable from gaining access to the internet itself" [1].

H. Morrison. BC Electronic Library Network (http://eln.bc.ca), W.A.C. Bennett Library, 7th Floor, Simon Fraser University, 8888 University Drive, Burnaby, BC V5A 1S6, Canada (e-mail: heatherm@eln.bc.ca, blog: http://poeticeconomics.blogspot.com).

A. Waller. University of Calgary Library, MLB 402B, 2500 University Drive NW, Calgary, AB T2N 1N4, Canada (e-mail: waller@ucalgary.ca).

${ }^{1}$ This article is based on a presentation given at the Canadian Health Libraries Association Conference, 14 May 2006, Vancouver, B.C.
The focus of the OA movement is scholarly, peer-reviewed research articles, which authors have traditionally given away, although the concept can apply to other types of resources, such as theses, dissertations, and grey literature.

Open access is free availability immediately on publication. There are other initiatives to increase access. For example, publishers can allow content to be freely accessed after an embargo period (usually 6-12 months); this can be better described as free back issues, rather than OA.

\section{Reasons for open access}

There are many reasons for supporting OA, including the following:

(i) Access to research information - The results of research and other scholarly activities must be disseminated to be useful. If an article that reports the results of research is hidden behind some sort of toll (toll access or TA), i.e., it requires a subscription or pay-per-view to access, this limits the amount of dissemination that is likely to occur, essentially to those libraries and users that can afford the subscription and (or) pay-per-view costs. The difference in dissemination is illustrated by a substantial body of research showing that $\mathrm{OA}$ articles are cited more often than articles hidden behind tolls [2,3].

(ii) Access to taxpayer-funded information and equity of access - Much of the research that is carried out in universities and elsewhere is funded with taxpayer dollars, usually supplied via large funding bodies. It is argued that no user should have to pay again, through either an individual or institutional subscription, for content that they have already paid for with their taxes. In the United States, there is a strong push along these lines from organizations such as the Alliance for Taxpayer Access 
(www.taxpayeraccess.org). In addition, there are strong arguments that the results of government-funded medical research, information that can affect people's lives, should be freely available to all, not just to those who can afford to pay. Open access can help to make more of this vital material available to all who need it, regardless of means.

(iii) Facilitates evidence-based medicine - Increased access for the practicing professional facilitates the practice of evidence-based medicine by making the evidence more accessible.

(iv) Author control - In the traditional world of scholarly journal publishing, the author has typically signed over all, or almost all, copyright to the publisher. In an OA environment, the author generally keeps the copyright and only grants the publisher the right to publish the article in that journal; all other rights are retained. Hence, in some ways, an author has more control in an OA situation than in the traditional environment.

(v) Library costs - Another impetus behind OA relates to the cost of toll access. Here is the situation: Using tax dollars, scholars are conducting research and publishing their research in journals that require up-front payment to be accessed by users. Who is providing the payment? Libraries are, via frequently very expensive subscription costs that increase at an average of $8 \%-12 \%$ annually, if not (much) more. These prices have had dire effects on the budgets of academic libraries for many years. Open access eliminates this total dependence on these up-front costs for access, something that may help libraries deal with serial budget difficulties.

It should be stressed that this does not mean that OA content is free to produce nor does it necessarily mean that libraries are off the hook for that payment. Open access advocates cannot be naïve about this; it costs to produce and distribute peer-reviewed scholarly material (though there are also ways to make the production cheaper).

\section{The main tracks of open access}

Generally speaking, there are two main tracks of open access: author self-archiving and open access publishing.

\section{Author self-archiving}

This involves authors (or a proxy) depositing a preprint and (or) a postprint of their articles in an open access repository (OAR). The Registry of Open Access Repositories (ROAR) currently lists more than 700 archives (http://archives.eprints.org/). These repositories can be cross-searched using tools such as OAIster (www.oaiaster.org), as a result of the Open Archives Initiative (OAI) (www.openarchives.org) protocol for metadata harvesting. There are more than 7.6 million items included in an OAIster search (not all are full text, some are bibliographic records only); the total is expected to exceed one billion items before the end of 2007 [4]. Users can also easily retrieve articles in repositories using common search tools such as Google and Google Scholar. Having articles in OARs provides a measure of preservation, as well as access.

Open access repositories can be institutional repositories, which are designed to collect and preserve the digital scholarly output of a university or similar body, or they can be subject-based repositories. The most important repository in the medical field is the subject repository PubMed Central (PMC) (www.pubmedcentral.com). A United Kingdom PMC (UKPMC) is in development.

There are 15-18 institutional repositories in Canada (maybe more) and many elsewhere in the world. Some are connected to hospitals; for instance, the Landspítali University Hospital in Iceland (http://landspitali.openrepository.com/lsh) has an archive for the work of its staff.

The question that is most often asked, especially by university researchers, about author self-archiving is How are the journal publishers with this? The answer is that the majority of publishers are fine with this, according to the publisher copyright policies and self-archiving page on the SHERPA Web site (www.sherpa.ac.uk/romeo.php). Most journal publishers, commercial and otherwise, big and small, allow deposition of preprints, postprints, or both.

For librarians, there are a number of library and information science (LIS) repositories, the largest of which is E-LIS, the OA archive for library and information studies, where searching and depositing articles is free (http://eprints.rclis.org/). E-LIS services include Metalis, a cross-search of LIS OA repositories.

\section{Open access publishing}

Open access publishing involves making articles open access in the process of publication. Some OA journals are new, while others have been converted from a subscription model. While author self-archiving is a very important path to $\mathrm{OA}$, and some believe it is the only means necessary, OA publishing has tended to be the focus of discussion.

There has been a great deal of activity in OA publishing. The Directory of Open Access Journals (DOAJ) (www.doaj.org), a librarian-vetted list of fully OA, peer-reviewed scholarly journals, currently lists nearly 2300 titles and has been adding titles at an average rate of 1.5 per day [4,5]. The DOAJ includes 320 health sciences journals. Free Medical Journals (www.freemedicaljournals.com) lists 1450 journals, though some of these are free only after a certain period of time and so are not truly OA. BioMed Central (BMC) (www.biomedcentral.com), one of the best known of the OA medical publishers, publishes around 175 OA titles. Other important OA publishers to be aware of include the Public Library of Science (PLoS), Hindawi Publishing, and Medknow Publications.

Traditional publishers are also entering the field, presenting either fully OA journals, such as Evidence-Based Complementary and Alternative Medicine (http://ecam.oxfordjournals.org/) from Oxford University Press, or "hybrid" journals, where journal issues feature a mix of OA and toll access articles.

Library and information science (LIS) journals are also publishing as OA; there are more than 60 LIS OA journals listed in DOAJ. Kudos to the Journal of the Canadian Health Libraries Association for moving to OA publishing with the Spring 2006 issue. Other OA LIS journals that may be of interest to the medical librarian include the Journal of the Medical Library Association, fully archived in PMC (http://www.pubmedcentral.nih.gov/tocrender.fcgi?action= archive\&journal=93); Evidence Based Library and Information Practice (http://ejournals.library.ualberta.ca/index.php/EBLIP/), Partnership: the Canadian Journal of Library and Informa- 
tion Practice and Research (forthcoming); and Biomedical Digital Libraries (http://www.bio-diglib.com/), a BMC journal.

Much of the discussion around OA publishing boils down to economics. How are quality OA publications created while still paying for the processes of publication and peer review? There are numerous possible ways of doing this; many could be used in combination. These include, but are not limited to, the following: (i) advertising, (ii) governmental support, (iii) grants, (iv) institutional support, (v) memberships, (vi) sponsorships, and (vii) submission charges.

The submission charge option has gathered a lot of interest and discussion, both pro and con. It is important to note that less than half of OA journals (47\%) charge submission fees [6], and many non-OA journals do charge a variety of submission fees (e.g., page charges, illustration charges, etc.). In fact, until about 20 years ago or so, some publishers charged authors completely for the costs of publication. BMC uses the submission-charges option, and traditional publishers are experimenting with submission charge-based OA publishing, whether for entire journals or as an option for individual articles (the "open choice" model). Some publishers charge a flat per-article fee; others have different charges for different journals, or the charges vary depending on whether or not the library is a subscriber or member. The following are examples of publisher submission charges: American Institute of Physics Author Select, US\$2000 per article; Blackwell Open Online, US\$2500 per article; Elsevier "sponsored articles", US\$3000 per article; Proceedings of the National Academy of Sciences, US $\$ 1000$ per article; Public Library of Science, US\$2000-\$2500 per article; Springer Open Choice, US\$3000 per article.

\section{Issues regarding open access}

The following are a few of the key issues regarding open access, in brief:

(i) Economic model for open access (publishing) - In many ways, this is the big question: OA is access-driven, but, especially in terms of publishing, how do we pay for it? It is likely that some OA options won't work with some disciplines but are quite compatible with others. For example, Mary Waltham's recent study indicated that a submission fee approach to OA is a very good model for some learned societies, but would not work for others [7].

(ii) Getting content into repositories - For institutional repositories, the number of articles deposited has been low, as little as $15 \%$ of articles that could have been deposited [8]. Evidence suggests that the only way to be successful is to mandate ("requirement policy"), at an institutional level, that articles have to be deposited. According to one survey, given a requirement, $81 \%$ of researchers will deposit their articles willingly (and others, grudgingly) [9], but those who work in universities know that mandating faculty to do anything can be difficult.

(iii) The library situation - If libraries are paying submission charges for their institutions or end up becoming OA publishers themselves, will subscription payments end up being replaced by production-based payments? What effect will this have on collections? Would this be a good thing or a bad thing? Also, what's the end game for libraries? If libraries end up in an all-OA world, what's to stop administrators from saying "It really is all free on the Internet now! Let's cut the library budget." How do libraries position themselves so that this doesn't happen, and they don't end up marginalized?

\section{Open access policy}

\section{Research funders}

The research funding community is leading in the development of OA policy for several very good reasons. Open access is the optimum method for disseminating the research that the agency has funded. As discussed previously, there is substantial evidence that OA articles are cited more often (more impact). For the research funder, this means (i) more research impact - more researchers to view the results and carry on the next steps; (ii) more real-world impact, particularly in an area like medicine, where expanding access enhances the ability of the practitioner to practice evidence-based medicine; and (iii) more visibility for the work of the funding agency per se, which can only help to ensure ongoing support for the work of the agency. It is not surprising then that research funders tend to be strongly in favour of OA.

\section{US National Institutes of Health: Public Access Policy}

The world's largest funder of medical research is the US National Institutes of Health (NIH). On 2 May 2005, the NIH implemented a Public Access Policy stating that NIH "requests and strongly encourages all investigators to make their NIH-funded, peer-reviewed, author's final manuscript available to other researchers and the public through the NIH National Library of Medicine's (NLM) PubMed Central (PMC) immediately after the final date of journal publication". Elsewhere, the policy statement allows for a delay period of up to 12 months, a compromise designed to assuage the concerns of publishers with immediate OA [10].

The NIH experience demonstrates why compliance with an OA policy must be required, not just requested. Even with strong encouragement, compliance with the policy has been less than 4\% [11]. The NIH developed a Public Access Working Group to address the deficiencies in this policy, and the recommendations of this group were to change the request to a requirement and to shorten the maximum permissible delay to 6 months from 12 months. Legislative efforts are currently underway in the US to address these deficiencies.

\section{US Federal Research Public Access Act of 2006}

Recently, a bill called the Federal Research Public Access Act of 2006 (FRPAA) was introduced in the US Senate by Senators Cornyn and Liebermann. If passed, this act would apply to all US federal funding agencies with extramural research portfolios of US\$100 million or more (11 agencies in all). Each agency would be required to implement a public access policy requiring research grantees to supply an electronic copy of their manuscript accepted for publication for OA within 6 months of publication. More information about FRPAA is available from the Scholarly Publication and Research Coalition Web site at http://www.arl.org/sparc/resources/frpaa.html 
or the Alliance for Taxpayer Access Web site at http://www. taxpayeraccess.org/frpaa/index.html.

When FRPAA was introduced, it was simultaneously endorsed by a number of the major library associations in the United States: the American Library Association, the Association of College and Research Libraries, the Association of Research Libraries, the Medical Library Association, the Special Libraries Association, and the American Association of Law Libraries. Could Canadian library associations work together in harmony to advocate for OA in this way?

\section{Wellcome Trust}

The second largest medical research funder in the world is the UK-based Wellcome Trust. The Wellcome Trust was the first research funder to implement a truly strong OA policy (the Wellcome Trust position statement in support of open and unrestricted access to published research is available at http://www.wellcome.ac.uk/doc_WTD002766.html). Wellcome Trust grantees are required to deposit a copy of the peerreviewed articles resulting from their funded research for OA in PMC within 6 months of publication. The Wellcome Trust policy applies to all grants awarded since October 2005. Articles covered by this policy are already beginning to appear in PMC. The Wellcome Trust is in the process of setting up UKPMC, which will mirror and complement the original PMC.

\section{UK Medical Research Council}

Effective 1 October 2006, recipients of new UK Medical Research Council funding awards are required to deposit peer-reviewed research results for OA in PMC (UKPMC, when available) at the earliest opportunity and certainly within 6 months of publication (http://www.mrc.ac.uk/open_access).

\section{Canadian Institutes for Health Research}

The Canadian Institutes for Health Research have a policy in development called Access to Products of Research. A survey was conducted in May 2006, and the results are expected shortly.

\section{Policy and open access archives (institutional repositories)}

Organizations are beginning to develop policies for their OA archives (institutional repositories) as well. Presently, 22 organizations have institutional policies requiring OA (see the Registry of Open Access Repositories Material Archiving Policies at http://www.eprints.org/openaccess/policysignup/). Organizations that have institutional repositories in place are beginning to find, like the $\mathrm{NIH}$, that simply providing the archive and strongly encouraging researchers to deposit their articles is not sufficient. To fill the archives, a requirement to deposit articles is essential. Once the requirement is in place, the archives fill up quite quickly. CERN, the world's largest particle physics laboratory, for example, now has more than 360000 full-text documents in its repository.

\section{Conclusions}

There is a great deal happening in open access that the medical librarian needs to be aware of. The resources themselves are significant and growing, with close to 2300 fully OA, peer-reviewed scholarly journals (320 of which are in the medical field), and OA titles are increasing at the rate of 1.5 per day. The extent of the growing resources in OA repositories is exemplified by the more than 7.6 million items encompassed by an OAIster search (not all items were full text), and this number is anticipated to grow to more than one billion items by the end of 2007. Open access policies are either in place or in consideration by all the major medical research funding agencies, such as the US National Institutes of Health, the Wellcome Trust, the UK Medical Research Council, and the Canadian Institutes of Health Research, among others. Implementation of OA policies will drive even greater growth in OA resources in general and in the medical field in particular. There are leadership roles for librarians in the OA environment. Librarians have long been leaders in OA advocacy and in educating faculty. There will be new roles for libraries, both academic and special, in building and filling institutional repositories, and some libraries are getting involved in publishing as well. There are also roles for libraries in finding solutions to the economics of OA, as well as potentially expanded roles in information literacy and research-level reference assistance, as the resources available to our users expand through OA.

\section{References}

1. Budapest Open Archives Initiative [Web page]. [Updated 2002 Feb 14; cited 2006 June 30.] Available from http:// www.soros.org/openaccess/read.shtml.

2. Eysenbach G. Citation advantage of open access articles. PLoS Biol [serial on the Internet]. 2006 May [cited 2006 Jun 30];4(5). Available from http://biology.plosjournals.org/perlserv/?request= get-document\&doi=10\%2E1371\%2Fjournal\%2Epbio\%2E0040157.

Eysenbach G. The open access advantage. J Med Internet Res [serial on the Internet]. 2006 [cited 2006 Jun 30];8(2). Available from http://www.jmir.org/2006/2/e8/.

3. Hitchock S. The effect of open access and downloads ('hits') on citation impact: a bibliography of studies [Web page]. Southampton (UK): The Open Citation Project [cited 2006 July 2]. Available from http://opcit.eprints.org/oacitation-biblio.html.

4. Morrison H. Dramatic Growth June 2006 [Web page]. The Imaginary Journal of Poetic Economics [updated 2006 June 30; cited $2006 \mathrm{Jul}$ 2]. Available from http://poeticeconomics. blogspot.com/2006/06/dramatic-growth-june-2006.html.

5. Morrison H. The dramatic growth of open access: implications and opportunities for resource sharing. Journal of Interlibrary Loan, Document Delivery \& Electronic Reserve [serial on the Internet]. 2006 [cited 2006 Jul 2];16(3). Available from http://eprints.rclis.org/archive/00004558/.

6. Kaufmann-Wills Group. Variations on Open Access: a study of the impact of alternative business models on financial and nonfinancial aspects of scholarly journals. Preliminary results [Web page]. London Book Fair; 2005 Mar 14 [cited 2006 July 2]. Available from http://www.alpsp.org/openacc.htm.

7. Waltham M. JISC: Learned society open access business models [Web page]. 2005 Jun [cited 2006 Jul 2]. Available from http://www.marywaltham.com/JISCReport.pdf.

8. Hajjem C. Étude de la variation de l'impact de citations des articles en accès libre [Web page]. 2005 Jul 28 [cited 2006 Jul 2]. Available from http://www.crsc.uqam.ca/lab/chawki/graphes/ EtudeImpact.htm.

9. Swan A, Brown S. Open access self-archiving: An author study [Web page]. Truro (UK): Key Perspectives Limited; 2005. 
Technical Report, Joint Information Systems Committee (JISC), UK FE and HE funding councils [cited 2006 Jun 30]. Available from http://cogprints.org/4385/.

10. US National Institutes of Health. NIH Public Access Policy [Web page]. Bethesda (Md.): National Institutes of Health [updated 2005 May; cited 2006 Jul 2]. Available from http://www. nhlbi.nih.gov/funding/policies/public-access.htm.

11. US Department of Health and Human Services, National Institutes of Health. Report on the NIH Public Access Policy [Web page]. Bethesda (Md.): National Institutes of Health; 2006 Jan [cited 2006 Jul 2]. Available from http://publicaccess.nih.gov/ Final_Report_20060201.pdf.

\section{Additional resources}

For further information and links to key resources, please see Peter Suber's Open Access Overview at http://www.earlham. edu/ peters/fos/overview.htm. For daily news, see Peter Suber's Open Access News at http://www.earlham.edu/ peters/ fos/fosblog.html. Open access resources and news most pertinent to librarians can be found on the OA Librarian blog at http://oalibrarian.blogspot.com (please note that the authors are part of the OA Librarian blog team). 
This article has been cited by:

1. GreysonDevon. 2011. Open access and health librarians in 2011. Journal of the Canadian Health Libraries Association 32:2, 45-49. [Abstract] [Full Text] [PDF] [PDF Plus] 